\title{
Jurnal

\section{Rancang Bangun Reaktor Pengolah Limbah Organik Menjadi Biogas Sebagai Bahan Bakar Alternatif Kendaraan Bermotor}

\section{Design And Development Of Organic Waste Reactors To Become Biogas As Fuel Alternative Fuel Motor}

\author{
I Wayan Diana Eka Pranata1, Kadek Rihendra Dantes', I Gede Wiratmaja1 \\ 1Program Studi Pend. Teknik Mesin Universitas Pendidikan Ganesha, Singaraja, Indonesia \\ e-mail: depwayan85@gmail.com, Rihendra-dantes@undiksha.ac.id, \\ wiratmaja@undiksha.ac.id
}

\begin{abstract}
Abstrak
Penelitian ini bertujuan untuk: 1) Untuk mengetahui proses perancangan desain reaktor biogas dari limbah organik rumah tangga. 2) tingkat kelayakan perancangan desain reaktor biogas dan tingkat kelayakan gas yang dihasilkan sebagai bahan bakar alternatif kendaraan bermotor. Penelitian ini menggunakan jenis penelitian (R\&D) Research and Development, dengan model pengembangan 4D (Four-D Models), yang terdiri dari 4 tahap yaitu tahap pendefinisian (define), tahap perancangan (design), tahap pengembangan (development), dan tahap penyebaran (deseminate).

Pada penelitian ini hanya dilakukan 3 tahap, yaitu tahap pendefenisian (define), tahap perancangan (design), dan tahap pengembangan (development). Hasil penelitian ini adalah 1) memahami perancangan desain reaktor biogas dari limbah organik rumah tangga, 2) mengetahui tingkat kelayakan perancangan desain reaktor biogas dan tingkat kelayakan gas yang dihasilkan sebagai bahan bakar alternatif kendaraan bermotor menurut ahli media, uji kelompok kecil dan uji kelompok besar pada masyarakat di Desa Pedawa Kecamatan Banjar. Penilaian dari ahli media memperoleh kriteria sangat layak untuk dilanjutkan ke tahapan berikutnya.

Dalam Uji Coba Kelompok Kecil memperoleh kriteria sangat layak dengan persentase nilai sebesar 85,66\%. Dalam Uji Coba Kelompok Besar memperoleh kriteria sangat layak dengan persentase nilai sebesar 86,06\%. Berdasarkan hasil tersebut dapat dinyatakan perancangan alat pengolah limbah organik rumah tangga sangat layak dari segi media, serta tanggapan dari mahasiswa, sehingga perancangan alat pengolah limbah organik rumah tangga ini dapat dinyatakan sangat layak digunakan dalam proses pengolahan limbah organik rumah tangga yang dapat mencemari lingkungan sekitar.
\end{abstract}

Kata Kunci : Perancangan Desain Reaktor, Biogas Portabel, Dan Energi Terbarukan.

\section{Abstract}

This study aims to: 1) To determine the design process of biogas reactor design from household organic waste. 2) the feasibility level of biogas reactor design and the feasibility of gas produced as an alternative fuel for motor vehicles. This research uses Research and Development (RED) type, with a 
4D (Four-D Models) development model, which consists of 4 stages: the defining stage, the design stage, the development stage, and the deployment stage (deseminate). In this study only 3 stages were carried out, namely the defining stage, the design phase, and the development stage. The results of this study are 1) understanding the design of biogas reactor designs from household organic waste, 2) knowing the feasibility of designing biogas reactor designs and the feasibility of the resulting gas as an alternative fuel for motor vehicles according to media experts, small group tests and large group tests on community in Pedawa Village, Banjar District. The assessment of the media experts obtained very feasible criteria to proceed to the next stage. In the Small Group Trial the criteria were very decent with a percentage value of $85.66 \%$. In the Large Group Trial the criteria were very decent with a percentage of value of $86.06 \%$. Based on these results it can be stated that the design of household organic waste treatment equipment is very feasible in terms of media, as well as the responses from students, so that the design of household organic waste treatment equipment can be declared very feasible to be used in the processing of household organic waste that can pollute the surrounding environment.

Keywords: Designing Reactor Designs, Portable Biogas, And Renewable Energy.

\section{PENDAHULUAN}

Energi sangat diperlukan dalam kehidupan sehari-hari. Sumber energi dapat berasal dari matahari, bahan bakar minyak, gas alam dan kayu bakar. Energi tersebut digunakan untuk keperluan rumah tangga seperti memasak dan penerangan. Kelangkaan bahan bakar minyak, yang salah satunya disebabkan oleh kenaikan harga minyak dunia yang signifikan, telah mendorong pemerintah untuk mengajak masyarakat mengatasi masalah energi secara bersama-sama (Kompas, 2008).

Upaya penghematan energi untuk bahan bakar seharusnya telah digerakkan sejak dahulu karena pasokan bahan bakar yang berasal dari minyak bumi, gas maupun batu bara adalah sumber energi fosil yang tidak dapat diperbarui (unrenewable), sedangkan permintaan terus naik, demikian pula dengan harganya sehingga tidak ada stabilitas keseimbangan antara permintaan dan penawaran. Salah satu jalan untuk menghemat bahan bakar minyak dan sumber energi yang unrenewable adalah dengan mencari sumber energi alternatif yang dapat diperbarui (renewable). Bahan bakar fosil seperti minyak bumi dan batubara merupakan sumber energi utama di Indonesia, akan tetapi sumber energi tersebut berdampak merusak lingkungan termasuk pencemaran udara, emisi gas rumah kaca dan pemanasan global. Permasalahan lain adalah tingginya harga bahan bakar fosil, kenaikan jumlah impor minyak bumi akibat konsumsi bahan bakar nasional, serta cadangan minyak bumi yang semakin menipis. Kebutuhan energi nasional diketahui bahwa lebih dari $50 \%$ penggunaannya didominasi oleh bahan bakar fosil, untuk itu pengembangan energi alternatif menjadi pilihan yang penting. Sudah saatnya semua negara memutuskan ketergantungan terhadap sumber energi fosil beralih ke sumber energi alternatif berbahan baku nabati yang sifatnya terbarukan (Hambali et al. 2007). Limbah organik berupa sisa makanan seperti, sisa buah-buahan \& sisa nasi yang tersisa dari limbah rumah tangga merupakan limbah organik yang menghasilkan limbah padat dan cair dalam jumlah yang lumayan besar dengan konsentrasi karbon yang tinggi, sehingga limbah organiksisa rumah tangga tersebut berpotensi mencemari lingkungan dan terjadinya penumpukan sampah organik yang tinggi, jika tidak dilakukan pengelolaan dengan baik maka limbah yang organik rumah tangga ini akan menimbulkan aroma yang sangat menyengat.

Limbah organik rumah tangga khususnya limbah dapur dari hasil sisa-sisa makanan berupa sisa buah-buahan \& sisa nasi yang tersisa merupakan bahan buangan dari usaha makanan dan limbah rumah tangga yang selama ini juga menjadi salah satu sumber masalah dalam kehidupan. Manusia sebagai penyebab menurunnya mutu lingkungan melalui 
pencemaran lingkungan, mengganggu kesehatan manusia dan juga sebagai salah satu menimbulkan bau yang sangat menyengat. Pada umumnya limbah organik rumah tangga hanya dibuang begitusaja di saluran air maupun di tempat pembuangan akhir yang akan menimbulkan bau \& mencemari lingkungan sekitar.

Untuk itu sudah selayaknya perlu adanya usaha pengolahan limbah organik rumah tangga menjadi suatu produk yang bisa dimanfaatkan manusia dan bersifat ramah lingkungan. Pengolahan limbah-limbah organik rumah tangga melalui proses anaerob atau fermentasi perlu digalakkan karena dapat menghasilkan biogas yang menjadi salah satu jenis bioenergi. Pengolahan limbah-limbah organik rumah tangga menjadi biogas ini diharapkan dapat mengurangi ketergantungan pada bahan bakar minyak yang mahal dan terbatas, mengurangi pencemaran lingkungan dan menjadikan peluang usaha bagi masyarakat karena produknya terutama pupuk kandang banyak dibutuhkan masyarakat dan juga sebagai pupuk tanaman. Prospek pengembangan teknologi biogas ini sangat besar terutama di lingkungan masyarakar dimana sampah bekas sisa-sisa makanan sebagian besarnya merupakan sampah organik seperti, limbah sayur-sayuran.

Biogas merupakan gas campuran metana $\left(\mathrm{CH}_{4}\right)$, karbondioksida $\left(\mathrm{CO}_{2}\right)$ dan gas lainnya yang didapat dari hasil penguraian bahan organik (seperti kotoran hewan, kotoran manusia, dan tumbuhan) oleh bakteri metanogen. Untuk menghasilkan biogas, bahan organik yang dibutuhkan, ditampung dalam biodigester. Proses penguraian bahan organik terjadi secara anaerob (tanpa oksigen). Biogas terbentuk pada hari ke 4-5 sesudah biodigester terisi penuh dan mencapai puncak pada hari ke 20-25. Biogas yang dihasilkan dari proses fermentasi limbah organik tidak memiliki kandungan gas yang $100 \%$ bisa terbakar. Produk biogas terdiri dari metana $\left(\mathrm{CH}_{4}\right)$ 55-75 \%, karbondioksida $\left(\mathrm{CO}_{2}\right)$ 25-45\%, nitrogen $\left(\mathrm{N}_{2}\right)$ 0-0,3 \%, hidrogen $\left(\mathrm{H}_{2}\right)$ 1-5 \%, hidrogen sulfida $\left(\mathrm{H}_{2} \mathrm{~S}\right)$ 0-3 \%, oksigen $\left(\mathrm{O}_{2}\right)$ 0,1-0,5\%, dan uap air (Burke, 2001).

Dari semua unsur tersebut yang berperan dalam menentukan kualitas biogas yaitu gas metana $\left(\mathrm{CH}_{4}\right)$ dan karbon dioksida $\left(\mathrm{CO}_{2}\right)$. Kemurnian metana dari hasil biogas tersebut jadi penting karena akan mempengaruhi nilai kalor yang dihasilkan. Bila kadar $\mathrm{CH}_{4}$ tinggi maka biogas tersebut akan memiliki nilai kalor yang tinggi. Sebaliknya jika kadar $\mathrm{CO}_{2}$ yang tinggi maka akan mengakibatkan nilai kalor biogas tersebut rendah. Biogas mempunyai nilai kalor yang cukup tinggi sekitar 4800 sampai $6700 \mathrm{kkal} / \mathrm{m}^{3}$, sebanyak $1000 \mathrm{ft} 3\left(28,32 \mathrm{~m}^{3}\right)$ biogas sama dengan galon (1 US gallon = 3,785 liter) butane atau 5,2 gallon gasolin (bensin) atau 4,6 gallon minyak diesel. Untuk memasak pada rumah tangga dengan 4-5 anggota keluarga cukup $150 \mathrm{ft} 3$ per hari (Goendi S, 2008).

Komponen terbesar biogas adalah Methana $\left(\mathrm{CH}_{4}, 54-80 \%\right.$ volume $)$ dan karbodioksida $\left(\mathrm{CO}_{2}, 20\right.$ - $45 \%$ volume) serta sejumlah kecil $\mathrm{H}_{2}, \mathrm{~N}_{2}$ dan $\mathrm{H}_{2} \mathrm{~S}$. (Siska, RSN, 2010). Biogas dihasilkan apabila bahan-bahan organik terurai menjadi senyawa-senyawa pembentuknya dalam keadaan tanpa oksigen anaerob. Fermentasi anaerobik ini biasa terjadi secara alami di tanah yang basah, seperti dasar danau dan di dalam tanah pada kedalaman tertentu. Proses fermentasi adalah penguraian bahan-bahan organik dengan bantuan mikroorganisme. Fermentasi anaerob dapat menghasilkan gas yang mengandung sedikitnya $50 \%$ metana. Gas inilah yang biasa disebut dengan biogas. Biogas dapat dihasilkan dari fermentasi sampah organik seperti sampah pasar, daun daunan, dan kotoran hewan yang berasal dari sapi, babi, kambing, kuda, atau yang lainnya, bahkan kotoran manusia sekalipun. Gas yang dihasilkan memiliki komposisi yang berbeda tergantung dari jenis hewan yang menghasilkannya.

Reaktor biogas merupakan suatu alat fermentasi bahan organik yang dirancang untuk menghasilkan gas metana yang terdiri dari bak penampung bahan, pipa penyalur gas dan balon panampung gas, reaktor ini secara umum terdiri dari beberapa jenis reaktor 
diantaranya adalah reaktor jenis kubah tetap (Fixed-dome), reaktor terapung (Floating drum), reaktor jenis balon dan reaktor fiberglass, dari beberapa jenis reaktor tersebut dibuat secara permanen pada lokasi tertentu dan membutuhkan investai besar, dalam pembuatan reaktor ini membutuhkan dana yang besar menyebabkan sebagian besar peternak tidak membuat reaktor tersebut, banyak inovasi yang telah dilakukan mengenai mahalnya pembangunan reaktor biogas salah satunya menggunakan reaktor dari drum besi tetapi dengan menggunakan bahan ini muncul masalah dalam pembangunan reaktor, terjadi korosif pada reaktor tersebut yang disebabkan karena kotoran sapi mengandung senyawa yang bersifat korosif, hal ini memicu untuk mencari bahan lain untuk menggantikan fungsi reaktor, untuk mengatasi yang demikian kami membuat drum plastik jenis HDPE (High Density Polyethylene) sebagi fungsi reaktor karena jenis plastik ini cukup tebal, tahan terhadap reaksi kimia dan harga relatif murah selain itu dengan menggunakan reaktor ini masyarakat yang tidak memiliki hewan ternak juga dapat menggunakannya melihat reaktor ini bersifat portabel (Abdul Khasman Basri, dkk. 2019).

Salah satu parameter yang mempengaruhi proses produksi biogas adalah tingkat pengenceran dan kandungan bahan organik di dalam biodigester. Jenis bahan organik yang digunakan sebagai bahan baku merupakan faktor yang sangat penting seperti sisa-sisa makan yang hampir setiap hari menghasilkan limbah. Limbah organik adalah bahan yang dapat dijadikan biogas seperti sayuran, buah-buahan dan sisa makanan. Proses pengolahan biogas dipengaruhi oleh beberapa faktor, diantaranya ialah produksi gas dan derajat keasaman $(\mathrm{pH})$. Keduanya berpengaruh pada kandungan gas-gas di dalam biogas itu sendiri. Jika produksi gas dan derajat keasaman $(\mathrm{pH})$ tidak memenuhi persyaratan, maka bakteri metanogenik tidak dapat hidup dan akhirnya akan berdampak pada proses pengolahan biogas.

Sampah rumah tangga salah satu limbah yang sifatnya setiap hari dikeluarkan dari proses mememasak. Untuk itu sampah organik dari limbah rumah tangga memerlukan starter untuk mempercepat terjadinya proses fermentasi, sehingga dibutuhkan campuran kotoran ternak sapi yang memiliki sumber bakteri untuk membantu proses dekomposisi sehingga mendapatkan hasil yang optimal (Wahyuni, 2013).

Adapun kekurangan biogas sebelumnya yaitu, membutuhkan biaya yang relatif lebih tinggi, tidak bisa dikemas dalam sebuah tabung, dan saat pengolahan diperlukan waktu yang cukup lama yaitu 37 hari. Maka peneliti tertarik untuk melakukan pengembangan biogas portabel, memiliki harga jual yang lebih ekonomis dibandingkan menggunakan gas elpiji $3 \mathrm{~kg}$ dan menggunakan feses sapi untuk mempercepat proses fermentasinya sehingga waktu yang diperlukan yaitu 7-14 hari telah menghasilkan gas metana.

Limbah yang dihasilkan setiap rumah warga akan setiap harinya menghasilkan limbah sisa memasak yang akan berdampat pada pencemaran lingkungan di sekitarnya dan membuat menumpuknya sampah organik yang akan menjadi sumber bau menyengat, maka untuk mengurangi jumlah sampah yang setiap hari semakin menumpuk. Dibuatlah penelitian tentang rancang bangun reaktor pengolah limbah organik menjadi biogas sebagai bahan bakar alternatif pada kendaraan bermotor.

\section{METODE}

Model pengembangan yang digunakan dalam penelitian ini adalah model pengembangan yang mengacu pada jenis pengembangan 4-D (Four-D model), yang terdiri dari 4 tahapan yaitu, tahap pendefenisian (define), tahap perancangan (design), tahap pengembangan (development), tahap penyebaran (deseminate). Didalam penelitian ini hanya dilakukan 3 tahapan saja yaitu, tahap pendefenisian (define), tahap perancangan (design), tahap pengembangan (development). Pada penelitian ini di gunakan model pengembangan 
4D (Four-D model) yang di kemukakan oleh (Thiagarajan, 1974:6-8) karena dalam penelitian ini peneliti mengembangan alat pengolah limbah rumah tangga menjadi biogas. Tahap Pendefinisian (Define) bertujuan menetapkan dan mendefinisikan kebutuhan-kebutuhan di bidang Energi Baru Terbarukan (EBT) di indonesia dengan menganalisis tujuan perancangan yang dilakukan. Tahap Perancangan (Design) dilakukan perancangan desain reaktor biogas portabel yang akan dikembangkan yaitu alat pengolah limbah organik rumah tangga menjadi biogas.

Di dalam tahap ini dilakukan beberapa tahapan diantaranya membuat desain reaktor, pemilihan jenis plastik, membuat angket responden, serta pemilihan komponen-komponen lainnya. Tahap Pengembangan (Develop), tujuan dari tahap pengembangan adalah untuk mengembangkan suatu alat dengan memproduksi komponen seperti wadah penampun, selang gas, kran/valve, pipa pvc, sambungan pipa, dan $T$ selang kemudian menggabungkannya agar menjadi produk final yang akan menghasilkan alat final yang siap untuk digunakan berdasarkan masukan para ahli dan data yang diperoleh dari uji coba. Kegiatan pada tahap ini adalah penilaian para ahli dan uji coba lapangan.

Adapun hal-hal yang divalidasi oleh validator mencakup: a) Validasi Isi Instrumen dalam validitas isi instrument berbagai cara yang dapat digunakan yang tujuannya adalah untuk melihat kesepakatan dari 2 pakar atau lebih dalam menilai keseluruhan konten. Aiken (1985) merumuskan formula Aiken's V untuk menghitung content validity coefficient yang didasarkan pada hasil penilaian dari panel ahli sebanyak $\mathrm{n}$ orang terhadap suatu item dari segi jauh mana item tersebut mewakili konstrak yang diukur. Formula yang di gunakan dalam penelitian ini adalah Aiken sebagai berikut (dalam Azwar, 2012):

$$
\mathrm{V}=\Sigma \mathrm{s} /[\mathrm{n}(\mathrm{c}-1)]
$$

Keterangan: $\mathrm{s}=$ angka yang diberikan peneliti dikurangi 1 Lo $=$ angka penilaian terendah (misalnya 1) $\mathrm{c}=$ angka penilaian tertinggi (misalnya 5) $\mathrm{r}=$ angka yang diberikan oleh penilai $\mathrm{n}=$ jumlah penilai

Adapun empat (4) orang ahli media yaitu bapak dosen yang memunyai keahlian dibidang media yang akan dinilai dan diberikan saran agar media secara fungsi dan tampilan menjadi lebih bagus dan menarik.

Instrumen yang digunakan untuk memperoleh sejumlah data yang diharapkan akan digunakan sebagai instrument pengumpulan data yaitu berupa angket. Angket yang digunakan untuk mengumpulkan data yang mengenai ketepatan komponen bahan ajar, ketepatan perancangan desain pembelajaran, ketepatan isi atau materi bahan ajar, ke menarikan dan keefektifan penggunaan media pembelajaran.

Penelitian dan pengembangan ini menggunakan teknik analisa data statistik deskriptif presentase dan jenis data yang digunakan adalah data kuantitatif. Statistik deskriptif yang digunakan untuk menganalisis data dengan cara mendeskripsikan atau menggambarkan data yang terkumpul sebagaimana adanya tanpa bermaksud membuat kesimpulan yang berlaku untuk umum atau generalisasi (Sugiono, 2013:147). Adapun instrumen yang digunakan adalah untuk lembar validasi ahli isi (materi), dan lembar angket tanggapan mahasiswa. 
Tabel 1. Bobot Nilai

\begin{tabular}{cc}
\hline Validasi Media & Bobot Nilai \\
\hline Sangat Setuju & 5 \\
Setuju & 4 \\
Kurang Setuju & 3 \\
Tidak Setuju & 2 \\
Sangat Tidak Setuju & 1 \\
\hline
\end{tabular}

Terdapat dua rumus yang digunakan dalam menganalisis data kuantitatif yang telah didapat. Data yang telah terkumpul dari uji coba produk selanjutnya diolah agar mendapat rata-rata dengan membuat persentase dengan rumus analisis per item soal dan keseluruhan. Data yang terdapat dalam angket tersebut dihitung untuk diperoleh skor, sehingga tercapai kesimpulan penelitian. Adapun rumus yang digunakan untuk pengolahan data sebagai berikut:

Rumus untuk Rata-rata per item soal:

$$
\mathrm{P}=\frac{F}{N}
$$

Keterangan:

$\mathrm{F}=$ Jumlah persentase keseluruhan subjek

$\mathrm{N}=$ Banyak Subjek

$\mathrm{P}=$ Persentase

Rumus untuk rata-rata keseluruhan :

$$
\mathrm{P}=\frac{\left.\sum \text { (Nilai Aangket }\right)}{n \times \text { Bobot Tertinggi }} \times 100
$$

Keterangan:

$\mathrm{P}=$ Persentase

$\Sigma=$ Jumlah

$\mathrm{n}=$ jumlah seluruh item angket

Sedangkan untuk penentuan kriteria kualifikasi tingkat kelayakan penilaian berdasarkan persentase dengan cara sebagai berikut :

1) Menentukan persentase skor maksimal $=100 \%$

2) Menentukan persentase skor minimal $=20 \%$

3) Menentukan lebar interval $=100-20=80$

4) Menentukan kelas interval, yaitu 5 (sangat layak, layak, cukup layak, kurang layak, tidak menarik).

5) Menentukan lebar rentangan interval $=80: 5=16$ 
Berdasarkan perhitungan dan cara di atas maka tabel distribusi range persentase dan kriteria kualitatif dapat ditetapkan seperti pada tabel 02.

Tabel 02. Kualifikasi Tingkat Kelayakan dengan Skala 5 (Sumber: Sofiyah:2010;40)

\begin{tabular}{|c|c|c|}
\hline Pencapaian & Kualifikasi & Keterangan \\
\hline $84,00 \%-100 \%$ & Sangat Layak & Tidak Perlu Revisi \\
\hline $68,00 \%-84,00 \%$ & Layak & Tidak Perlu Revisi \\
\hline $52,00 \%-68,00 \%$ & Cukup Layak & Revisi \\
\hline $36,00 \%-52,00 \%$ & Kurang Layak & Revisi \\
\hline $20,00 \%-36,00 \%$ & Tidak Layak & Revisi \\
\hline
\end{tabular}

Jadi untuk mendapatkan media yang layak maka persentase minimal yang harus didapatkan yaitu $68,00 \%$ sehingga media yang dikembangkan sudah dapat dilanjutkan ke tahapan berikutnya.

\section{HASIL DAN PEMBAHASAN}

Hasil dari penelitian dan pengembangan ini adalah sebuah rancang bangun suatu alat yang menghasilkan produk biogas dari limbah rumah tangga Sebagai Bahan Bakar Alternatif Kendaraan Bermotor. Tentunya rancang bangun prototype reaktor ini sudah diuji tingkat kelayakan oleh para ahli/pakar dan tingkat keberterimaannya oleh masyarakat pengguna. Dari penilaian ahli media terhadap desain dari reaktor biogas portabel, diperoleh hasil dari tiap uji judges sangat layak sehingga dapat dilanjutkan ke uji keberterimaan oleh masyarakat meliputi uji coba pada kelompok kecil dan kelompok besar. Kelompok kecil terdiri dari 5 orang dan kelompok besar terdiri dari 25 orang. Dari hasil uji coba kelompok kecil didapatkan hasil persentase keberterimaan sebesar 85,66 \% dan masuk dalam katagori tanpa revisi dan hasil uji coba kelompok besar memperoleh nilai persentase sebesar $86,06 \%$ dan masuk dalam katagori tanpa revisi.

\section{KESIMPULAN DAN SARAN}

Kesimpulan dari penelitian pengembangan rancang bangun reaktor limbah pengolah limbah organik menjadi biogas sebaga bahan bakar alternatif kendaraan bermotor yaitu berdasarkan perancangan desain dari reaktor biogas portabel, menggunakan Four-D Model. Dihasilkan desain reaktor dengan memiliki ukuran diameter tabung $40 \mathrm{~cm}$, dan tinggi tabung $57 \mathrm{~cm}$. Dan dari penilaian ahli media dan uji coba kelompok dapat disimpulkan desain dan prototype reaktor ini dinyatakan sangat layak untuk dikembangkan lebih lanjut.

Berdasarkan pemaparan dari penelitian dan pengembangan yang telah dilakukan, maka saran yang dapat disampaikan terkait pengembangan alat pengolah limbah organik menjadi biogas yaitu bagi Peneliti Lain, alat pengolah limbah organik menjadi biogas ini bisa dikembangkan lagi dari segi desain alat, volume limbah yang digunakan, \& kapasitas digester yang digunakan. Penelitian ini juga bisa digunakan sebagai referensi penelitian terkait pengembangan alat pengolah limbah organik menjadi biogas. Saat proses pemasangan saluran inlet dan penutup reaktor agar lebih rapat supaya tidak terjadi kebocoran yang menyebabkan kegagalan pada hasil gas yang dihasilkan pada reaktor dan perlunya penyempurnaan lagi dari perancangan reaktor biogas dari limbah organik, yang nantinya dapat diterapkan keluaran gas yang dihasilkan pada kendaraan bermotor konvensional. 


\section{UCAPAN TERIMAKASIH}

Tentunya dalam pelaksanaan penelitian ini penulis banyak sekali memperoleh bantuan dari berbagai pihak. Dalam kesempatan ini peneliti ingin mengucapkan rasa terima kasih serta penghargaan yang setingi - tingginya sebagai tanda syukur dan hormat peneliti kepada :

1. Prof. Dr. Nyoman Jampel, M.Pd. selaku Rektor Universitas Pendidikan Ganesha.

2. Dr. I Gede Sudirtha, S.Pd., M.Pd. selaku Dekan Fakultas Teknik dan Kejuruan di Universitas Pendidikan Ganesha.

3. Dr. Kadek Rihendra Dantes, S.T., M.T, selaku Ketua Jurusan Teknologi Industri di Universitas Pendidikan Ganesha.

4. Dr. Kadek Rihendra Dantes, S.T.,M.T selaku pembimbing I yang selalu mengayomi dengan sabar, memberikan tuntunan, dan bantuan, serta semangat kepada penulis.

5. I Gede Wiratmaja, S.T.,M.T selaku dosen pembimbing II yang dimana selalu memberikan arahan-arahan guna memotivasi penulis.

6. Staff dosen di Program Studi Pendidikan Teknik Mesin Universitas Pendidikan Ganesha, yang telah banyak membantu selama penulisan mengikuti studi di Program Studi Pendidikan Teknik Mesin.

\section{DAFTAR RUJUKAN}

Aiken L. R. (1985).Three Coeffcient for Analyzing The Reliability and Validity of Ratings. Education and Psychological Measurement. 45,131-142.

Akhadi, Mukhlis.(2009). Ekologi Energi Mengenai Dampak Lingkungan dalam Pemanfaatan Sumber-Sumber Energi. Jakarta: Graha Ilmu.

Arikunto, Suharsimi. (2006). Metodelogi Penelitian. Yogyakarta: Bina Aksara. . 2006. Prosedur Penelitian Suatu Pendekatan Praktik. Jakarta: Rineka Cipta.

Arsyad, S. (2010). Konservasi Tanah dan Air. Bogor: Institut Petanian Bogor Press.

Badan Pusat Statistik. 2014. Kecamatan Getasan Dalam Angka Tahun 2014. Semarang: BPS. 